\title{
Programa quirúrgico para residentes de Otorrinolaringología: De la teoría a la práctica
}

\author{
Surgical training program for ORL residents: From theory to practice
}

Carolina Castillo T', Samanta Ruz G', Hayo Breinbauer K², Sergio Cárcamo S'.

\section{RESUMEN}

Introducción: La formación de médicos especialistas en Otorrinolaringología es una necesidad en nuestro país, lo que debe incluir un aprendizaje de contenidos teóricos y adquisición de habilidades prácticas.

Objetivo: Evaluar el cumplimiento de los objetivos prácticos planteados por el programa de formación de especialistas de la Escuela de Postgrado de la Universidad de Chile.

Material y método: Estudio retrospectivo, descriptivo a partir de los libros del pabellón del Servicio de Atorrinolaringología del Hospital San Juan de Dios, en el período 1996-2007.

Resultados: 8 cumplimiento global de los objetivos es de $57,3 \%$.

Discusión y conclusión: Diversos factores pueden explicar el resultado. Consideramos el más importante la falta de actualización del programa a los avances tecnológicos de la especialidad y a la realidad epidemiológica nacional.

Palabras clave: Residente de otorrinolaringología, programa de formación práctica, docencia.

\section{ABSTRACT}

Introduction. Adequate specialty training in otorhinolaryngology should include both theoretical learning and the acquisition of practical skills.

Aim. To assess the practical skills objectives reached by the medical specialty training program at the University of Chile Postgraduate School.

Material and Method. Retrospective and descriptive study based on the surgical ward medical records of the Atorhinolaryngology Department of San Juan de Dios Hospital, between 1996 and 2007.

Results. The overall rate of objectives reached was $57,3 \%$.

Discussion and Conclusion. Several factors may account for the results. Most important in our view is the Program failure to keep updated according to the specialty new technological advances and the local epidemiological reality.

Keywords: Otorhinolaryngology resident, practical skills acquisition program, teaching.

Servicio Otorrinolaringología, Hospital San Juan de Dios.

1 Médico, Servicio Aorrinolaringología, Hospital San Juan de Dios

2 Médico Grujano, Universidad de Chile. 


\section{INTRODUCCIÓN}

La formación de médicos especialistas en otorrinolaringología (ORL) es una necesidad en nuestro país. Esto obedece a la demanda de servicios en esta rama y a la importancia que, a nuestro juicio, tienen las actividades docentes hospitalarias. Este punto es tan importante como el primero, ya que eleva el nivel académico, promueve la superación de los integrantes de un servicio, obligando a una constante revisión de la literatura, a una excelencia en el estudio clínico de los pacientes y al perfeccionamiento de las técnicas quirúrgicas. Por otro lado, hace menos rutinaria la prestación de los servicios médicos'.

日 programa de posgrado de la especialidad impartido por la Universidad de Chile contempla tres años de formación con distintas rotaciones, que son realizadas en cuatro centros docentes asistenciales, todos acreditados por la Asociación de Facultades de Medicina de Chile (ASOFAMECH). En éstos se realizan las actividades prácticas, las que dependen de flujo de pacientes y oportunidad quirúrgica de cada servicio, a diferencia del curso teórico que se dicta en la Sociedad Chilena de Otorrinolaringología, Medicina y Cirugía de Cabeza y Cuello (SOCHORL), común para todos los residentes? ${ }^{2}$.

日 Servicio de Otorrinolaringología del Hospital San Juan de Dios (HSJDD), existe como centro formador desde 1956 y desde sus inicios ha sido acreditado por la Universidad de Chile, entregando un promedio de dos especialistas por año ${ }^{3}$. La práctica quirúrgica se realiza únicamente en este centro, a cargo tanto de docentes acreditados por la universidad como de médicos especialistas interesados en la formación de residentes. $日$ programa práctico contempla la ejecución de cirugías de diferente complejidad, que van en directa relación al año cursado por el residente, estableciéndose así tres niveles2: (Anexo №1).

I. Otorrinolaringología General, Ambulatoria y Hospitalaria

II. Otología

III. Patología de Cabeza y Cuello

Son pocos los estudios que evalúan si se cumplen los objetivos de este programa, el único publicado es uno subjetivo a partir de una encuesta a 18 becados que cursaban diferentes años de residencia, que concluyó que el $100 \%$ de ellos no cumple con todos los objetivos propuestos en el programa, poniendo en evidencia las fortalezas y falencias de éste, y dictando directrices para su mejoría 4 , que aún no se han realizado.

日 presente trabajo busca objetivar en nuestro centro:

1. Procedimientos quirúrgicos realizados por los residentes de otorrinolaringología según el año cursado.

2. Correlacionar lo anterior con el programa establecido por la Escuela de Posgrado, para evaluar si los objetivos planteados por éste se cumplen en forma adecuada.

3. Evaluar el perfil de los docentes que participan en la formación de becados.

\section{MATERIAL Y MÉTODO}

Estudio retrospectivo. Se revisaron los libros de pabellón del Servicio de Otorrinolaringología del Hospital San Juan de Dios, cuyo registro es responsabilidad de los médicos que participan en la cirugía 日 período estudiado va entre abril 1996 y abril 2007. Se registró: fecha, nombre del paciente, ficha clínica, edad, diagnóstico, cirugía realizada, cirujanos involucrados y tipo de anestesia.

En cuanto a los médicos presentes en cada procedimiento, se determinó si éstos correspondían a especialistas contratados por el Ministerio de Salud (MINSAL), por la universidad o residentes en sus distintos años de formación.

Se clasificaron los procedimientos en los 3 niveles de complejidad descritos, utilizando como referencia el programa de la Escuela de Posgrado para la formación de especialista en Otorrinolaringología de la Universidad de Chile, que define los objetivos prácticos a cumplir por año de residencia. Cabe destacar que la Escuela de Posgrado sólo otorga validez al cumplimiento de los objetivos si el médico en formación figura como cirujano o primer ayudante.

Se determinó el porcentaje de logro para cada objetivo como el porcentaje de residentes del total que participaron al menos unavezcomo primer cirujano en los procedimientos planteados por el programa 
Anexo № 1

PROGRAMA DE FORMACION DE ESPECIALISTA EN OTORRINOLARINGOLOGIA DE LA UNIVERSIDAD DE CHILE

PROGRAMA PRÁCTICO: Se realiza por rotaciones asignándose un tutor en cada una de ellas.

Durante la rotación el alumno verá pacientes ambulatorios en el policlínico de la especialidad, evolucionará pacientes con tratamiento médico complejo y quirúrgico en las salas de hospitalización, interconsultas; asistirá a intervenciones quirúrgicas como ayudante y luego como cirujano, todo ello asistido por su tutor o por el médico que se le asigne.

- Se destina una tarde a la semana para realizar prácticas en hueso temporal.

\section{2.- ADMINISTRACION DOCENTE:}

\subsection{ROTACIONES OBLIGADAS QUE COMPRENDEE PROGRAMA:}

Primera rotación: OTORRINOLARINGOLOGIA GENERAL, AMBULATORIA Y HOSPITALARIA

- Duración: 1 año

- Objetivos:

1.- Que el alumno, al final de su pasada pueda realizar como cirujano los siguientes procedimientos e intervenciones quirúrgicas de baja y mediana complejidad.

- Técnicas quirúrgicas básicas. Evaluación y diagnóstico correcto del paciente con alteraciones de la voz y el lenguaje.

- Fibroscopía rinofaringolaríngea

- Laringoscopías directas con y sin microscopio.

- Extirpación nódulos vocales, pólipos y papilomas laríngeos.

- Decorticación cordal.

- Biopsias

- Adenoidectomías

- Amigdalectomías

- Punción y aspiración timpánica con y sin colocación de tubos de ventilación.

- Grugía de senos maxilares.

- Polipectomías nasales.

- Cauterización o resección de cornetes.

2.- Que el alumno, al final de la pasada tenga conocimiento y experiencia como para participar como ayudante en las siguientes intervenciones quirúrgicas de alta complejidad.

- Septoplastías

- Rinoplastías

Segunda rotación: OTOLOGA

Duración: 1 año

Objetivos:

1.- Que el alumno, al final del su pasada pueda realizar personalmente los siguientes procedimientos e intervenciones quirúrgicas de baja y mediana complejidad.

- Realización e interpretación de exámenes audiométricos.

- Examen otoneurológico.

- Procedimientos ambulatorios otomicroscópicos. Aseo de cavidades. Aspiración de secreciones,extracción de tapones aéreos epiteliales, cuerpos extraños, cierre de perforaciones timpánicas.

- Punción y aspiración de efusiones timpánicas con o sin colocación de tubos de ventilación.

- Timpanoplastías.

- Mastoidectomias.

- Vaciamiento timpanomastoídeo(clásico o modificado)

2.- Que el alumno al final de su pasada, realice personalmente, en hueso temporal, las siguientes técnicas quirúrgicas de alta complejidad.

- Descompresión del facial intratemporal.

- Laberintectomías.

- Descompresión del saco endolinfático.

- Abordaje del conducto auditivo interno 
Tercera rotación: PATOLOGIA DE CABEZA Y OU日LO.

Duración: 1 año

Objetivos:

1.- Que el alumno, al final de su pasada pueda realizar personalmente los siguientes procedimientos e intervenciones quirúrgicas de baja y mediana complejidad.

- Diagnóstico y evaluación del paciente oncológico.

- Traqueostomía

- Punción del seno maxilar.

- Girugía de cavidades paranasales (etmoides y frontal).

- Microcirugía nasal y de seno maxilar.

- Tratamiento quirúrgico de la epistaxis.

- Ligadura de la maxilar interna.

- Ligadura de la carótida externa.

- Tratamiento de la fractura nasal.

2.- Que el alumno, al final de su pasada tenga experiencia y conocimientos para actuar como primer ayudante en las siguientes intervenciones de alta complejidad.

- Laringectomías.

- Vaciamiento cervical radical.

- Parotidectomías.

- Submaxilectomías.

- Maxilectomías y etmoidectomías (radical y parcial)

- Fractura malar.

- Fractura del tercio superior de la cara.

- Fractura del tercio medio de la cara.

- Abordaje del fibroangioma rinofaríngeo.

Para la evaluación de la participación docente, se consideró como una "cirugía docente" todo procedimiento donde aparecía un miembro del staff y un residente. De estas cirugías se determinó cuántos docentes correspondían a especialistas contratados por la universidad o por el servicio.

Se realizaron pruebas estadísticas de comparación de promedios t-student y comparación de proporciones z-test según corresponde, utilizando software estadístico SPSS 15.0.

\section{RESULTADOS}

En el período estudiado se formaron un total de 19 especialistas: 3 derivados del concurso de última promoción, 3 de promociones anteriores, y 13 de etapa de destinación y formación (ex generales de zona).

Se realizaron un total de 8.875 cirugías, con un promedio de 780 cirugías/año. De ellas según la clasificación entregada por la Escuela de Posgrado $70,7 \%$ correspondieron a nivel I, $16,7 \%$ nivel II y $9 \%$ a nivel III. En la Tabla 1 se observan los procedimientos quirúrgicos más frecuentes por nivel.
Del total de cirugías, los residentes participaron en $90,7 \%$ de ellas, independiente de su rol en éstas, siendo cirujano en el $44,4 \%$. En relación a la complejidad de la cirugía intervinieron en $51 \%$ de los procedimientos de nivel I, 32,1\% de nivel II y $32,3 \%$ de nivel III. En la Tabla 2 se detalla la participación según año de residencia.

Cuando el residente operó como primer cirujano, fue acompañado por un staff en el $15,9 \%$ de los procedimientos de nivel I, significativamente menos $(p<0,01)$ que en nivel II $(63,2 \%)$ y en nivel III (56\%). No hay diferencias significativas entre nivel II y III.

En relación al cumplimiento de los objetivos de la escuela de postgrado por año de residencia se observa que:

- Residente de primer año: Cumple con los obje tivos de la Escuela de Posgrado en $72 \%$. 日 desglose por ítem se observa en la Tabla 3.

- Residente de segundo año: Cumple con lo descrito en $73 \%$. 日 detalle se observa en la Tabla 4.

- Residente de tercer año: Oumple con $27 \%$ de los objetivos planteados por la Escuela de Posgrado. Detalle en Tabla 5. 
Tabla 1. Procedimientos quirúrgicos más frecuentes por nivel de complejidad

\begin{tabular}{|lcc|}
\hline Nivel de complejidad & Tipo de cirugías & Promedio/año \\
\hline Bajo & Adenoamigdalectomía & 304 \\
\multirow{3}{*}{ Mediana } & Punción aspirativa transtimpánica & 90 \\
& Timpanoplastías & 44 \\
Alta & Radical de oído & 33 \\
& Traqueostomía & 36 \\
& Rinoseptoplastía & 26 \\
\hline
\end{tabular}

Tabla 2. Participación de los residentes en procedimientos quirúrgicos según complejidad y año de residencia

\begin{tabular}{|lcccc|}
\hline Nivel de complejidad & Primero & $\begin{array}{c}\text { Año de residencia } \\
\text { Segundo }\end{array}$ & Tercero & Total \\
\hline Baja & $16,6 \%$ & $20 \%$ & $14,5 \%$ & $51 \%$ \\
Mediana & $5 \%$ & $11,3 \%$ & $15,9 \%$ & $32,1 \%$ \\
Alta & $7 \%$ & $12,4 \%$ & $12,7 \%$ & $32,3 \%$ \\
\hline
\end{tabular}

Tabla 3. Cumplimiento de objetivos del programa quirúrgico para becados de primer año

\begin{tabular}{|lcc|}
\hline Procedimientos de nivel I & Logrado* & $\begin{array}{c}\text { Procedimientos por } \\
\text { Becado a 1 año** }\end{array}$ \\
\hline Como cirujano & & 53 \\
Biopsias & $100 \%$ & 23,5 \\
Adenoidectomía & $100 \%$ & 28,8 \\
Amigdalectomía & $100 \%$ & 7,2 \\
Punción aspirativa transtimpánica & $100 \%$ & 0 \\
Polipectomía nasales & $0 \%$ & 2 \\
Cauterización o resección de cornetes & $100 \%$ & 1,5 \\
Laringoscopía directa con o sin microscopía & $66,7 \%$ & 1,5 \\
Extirpación de nódulos/pólipos/papilomas & $63,2 \%$ & 0,3 \\
Crugía de senos maxilares & $27,8 \%$ & 3,7 \\
Como ayudante & & \\
Rinoseptoplastía/Septoplastía & $66,7 \%$ & 3 \\
\hline
\end{tabular}

* Porcentaje del total de becados evaluados en participar de cadaprocedimiento como primer cirujano al menos unavez

* * Cantidad promedio de cada procedimiento realizado durante el primer año de residencia.

Tabla 4. Cumplimiento de objetivos del programa quirúrgico para becados de segundo año

\begin{tabular}{|lcc|}
\hline Procedimientos nivel II como cirujano & Logrado* & $\begin{array}{c}\text { Procedimientos por becado } \\
\text { a 2 años }\end{array}$ \\
\hline Punción aspirativa transtimpánica & $100 \%$ & 34,1 \\
Timpanoplastías & $100 \%$ & 10,3 \\
Vaciamiento tímpano mastoídeo & $93,3 \%$ & 9,1 \\
Técnicas de alta complejidad en hueso temporal & $0 \%$ & 0 \\
\hline
\end{tabular}

* Porcentaje del total de becados evaluados en participar de cadaprocedimiento como primer cirujano al menos unavez

** Cantidad promedio de cada procedimiento realizado durante los dos primeros años de residencia. 
Tabla 5. Cumplimiento de objetivos del programa quirúrgico para becados de tercer año

\begin{tabular}{|lcc|}
\hline Procedimientos nivel III & Logrado & $\begin{array}{c}\text { Procedimientos por becado } \\
\text { a } 3 \text { años }\end{array}$ \\
\hline Como cirujano & & \\
Traqueostomía & $100 \%$ & 9,7 \\
Grugía endoscópica funcional & $66,7 \%$ & 1,8 \\
Tratamiento quirúrgico de epistaxis & $0 \%$ & 0 \\
Ligadura maxilar interna & $0 \%$ & 0 \\
Ligadura de carótida externa & $5,3 \%$ & 0,33 \\
Tratamiento de la fractura nasal & $100 \%$ & 33,9 \\
Como ayudante & & \\
Laringectomía & $38,5 \%$ & 0,76 \\
Vaciamiento cervical radical & $15,4 \%$ & 0,23 \\
Parotidectomía & $23,1 \%$ & 0,38 \\
Submandibulectomía & $7,7 \%$ & 0,07 \\
Maxilectomía y etmoidectomía & $46,2 \%$ & 0,46 \\
Fractura malar & $0 \%$ & 0 \\
Fractura tercio superior de la cara & $0 \%$ & 0 \\
Fractura tercio medio de la cara & $0 \%$ & 0 \\
Abordaje del fibroangioma rinofaríngeo & $23,1 \%$ & 0,23 \\
Grugía cráneo facial & $0 \%$ & 0 \\
\hline
\end{tabular}

* Porcentaje del total de becados evaluados en participar de cada procedimiento como primer cirujano al menos una vez.

* * Cantidad promedio de cada procedimiento realizado durante los tres años de residencia.

Tabla 6. Promedio de procedimientos anuales en que un cirujano realiza docencia

\begin{tabular}{|lrccc|}
\hline & Baja* $^{*}$ & Moderada & Alta $^{*}$ & Total $^{*}$ \\
\hline U de Chile & 12,2 & 8,2 & 7,2 & 27,6 \\
MINSAL & 8,4 & 7,3 & 4,5 & 21,2 \\
\hline
\end{tabular}

${ }^{*} p<0,05$

\section{Docencia}

En el HSJDD en el período estudiado hay 12 staff, de los cuales 4 son docentes de la Universidad de Chile y 8 pertenecientes al Servicio de Salud Metropolitano Occidente, con cargos de 11 y 22 horas semanales para ambos grupos. Al analizar las cirugías "docentes" en las que participan los becados, en $58,88 \%$ son asesorados por alguno de los docentes del MINSAL (Ministerio de Salud), mientras que $41,12 \%$ por alguno de los docentes de la Universidad de Chile, siendo esta diferencia estadísticamente significativa $(z<0,01)$.
Luego indagamos en el aporte individual de cada docente, según era del MINSAL, o contratado por la Universidad. Se estandarizó el número de procedimientos anuales en los que un especialista ejercía docencia, corregido por horas semanales y años de servicio. Vemos el resultado en la Tabla 6, donde se evidencia que un docente contratado por la Universidad de Chile asesora a becados en un promedio de 27,6 procedimientos anuales, lo que es significativamente mayor $(p<0,05)$ al promedio de cirugías asesoradas por un especialista del MINSAL (21,2 procedimientos). A desglosar esta diferencia por nivel de complejidad (Tabla 6) encontramos que aunque en cada nivel, especialistas de la universidad apoyan en un mayor número de procedimientos, esto es sólo estadísticamente significativo en cirugías de baja y alta complejidad (nivel I y III).

\section{DISCUSIÓN Y CONCLUSIONES}

Se decidió estudiar el período comprendido entre abril 1996 y abril 2007, con el fin de evitar el sesgo 
que se produce por cambios en el programa, lo que no ha sucedido desde 1995.

Utilizamos los libros de pabellón para el registro de las cirugías, pues siempre son completados por los becados que participan en éstas, lo que hace que su registro sea objetivo y confiable.

Nuestro centro cumple con los objetivos planteados por la Escuela de Posgrado en 57,3\%.

Con respecto al residente de primer año, éste realiza un número menor de procedimientos compa rado con sus equivalentes de segundo y tercer año, debido a que durante los primeros 3 meses de su residencia no participa activamente en el pabellón y por la curva de aprendizaje que se da en la formación de cualquier especialista Sin embargo, cumple con $72 \%$ de los objetivos planteados. Las cirugías de mayor frecuencia son realizadas en $100 \%$. 1 déficit está dado fundamentalmente por las polipectomías nasales lo cual puede ser explicado porque han sido reemplazados por la cirugía endoscópica funcional. Respecto de las laringoscopías directas, si bien no se cumple a cabalidad durante el primer año, el $100 \%$ de los residentes lo logra en los primeros 18 meses de formación. Destaca que resuelven patologías que no están incorporadas dentro del programa de posgrado como: fístula y papilomas preauriculares, sección de frenillo lingual, procedimientos bajo anestesia local (reducciones nasales, biopsias nasales, punción espirativa transtimpánica), taponamientos posteriores y anteriores; cauterización nasal, drenaje de he matoma septal y de otohematomas; ránulas, esofagoscopía rígida, drenaje de abscesos submandibulares y periamigdalinos; y extracción de cuerpo extraño nasal, ótico y esofágico.

日 residente de segundo año cumple los objetivos propuestos en $73,3 \%$. La única falencia está dada por el trabajo en hueso temporal, que se realiza sólo en algunos centros ${ }^{2}$, por la dificultad en el acceso a este material y los problemas médicolegales derivados de esto. Destaca que la punción aspirativa transtimpánica (PAT) se vuelve a considerar un objetivo, que se supone debió haber sido cumplido en primer año.

Respecto del residente de tercer año, si bien el resultado neto es francamente deficiente, al estudiar el detalle se observa que de los procedimientos que debe realizar como primer cirujano, sólo no ejecuta ligaduras arteriales. Oreemos que la causa de esta falencia estádada porqueson procedimientos de muy baja frecuencia y que han sido desplazados por otros diferentes. En relación a las ayudantías que no efectúa hay diversos factores que lo explican: baja frecuencia, no resolución de patología traumática facial por ORL en nuestro centro; por otro lado, no contamos con neurocirujanos en nuestro Hospital, lo que limita cualquier abordaje neuroquirúrgico. Aro punto a destacar es que en cirugías de nivel III existe $44 \%$ que son abordadas sólo por becados, lo que se explica fundamentalmente por traqueostomías, que si bien son nivel III para el programa, son realizadas en nuestro centro desde el primer año de residencia Resalta también, que en todas las laringectomías y vaciamientos cervicales hay un becado presente como ayudante, pero que no es el primero, que es lo que se considera dentro del programa

日 incumplimiento de los objetivos podría ser explicado por diferentes variables:

1. Problemas locales, tales como flujo de pacientes o incidencia de enfermedades del sector $u$ oportunidad quirúrgica. En nuestro centro en particular las 2 primeras variables son poco modificables. Con respecto a la oportunidad quirúrgica los residentes participan en más del $90 \%$ de las cirugías realizadas, pese a que sólo representan el $33 \%$ de los cirujanos del servicio.

2. Falta de información o de interés por parte del residente: es un factor con baja ingerencia, dado que el programa es discutido al ingreso del becado al servicio.

3. Programa extemporáneo: Oreemos que es el factor preponderante, dado que contempla objetivos, quesi bien pueden ser trascendentes, son de bajo impacto epidemiológico, por lo tanto no se presentará la oportunidad quirúrgica para realizarlo y por ende aprenderlo. Además, no contempla otros, que a nuestro parecer, son fundamentales en la práctica clínica habitual por su frecuenciay urgenciarelativa por las complica ciones derivadas de su mal manejo; tales como: taponamientos anteriores, posteriores, resección de fístulas preauriculares, sección de frenillo lingual y drenaje de abscesos, entre otros.

Al analizar el perfil de los docentes que participan en la formación de los residentes se observa un gran compromiso por parte de todo el servicio en la adquisición de las habilidades quirúrgicas. Si bien, a simple vista, son más las cirugías asesoradas por 
staff del MINSAL, al ajustarlas para hacer los 2 grupos comparables, se observa que los docentes de la Universidad de Chile efectivamente participan individualmente en un mayor número de actividades formativas, diferencia que es estadísticamente significativa para las cirugías de baja y alta complejidad.

Dados los hallazgos derivados de este estudio, consideramos prioritario que cada centro formador reproduzca este análisis y ponga en evidencia las falencias locales del programa práctico, de manera que pueda reestructurarse y actualizarse dado que esto no se ejecuta desde 1995 y plantear metas quirúrgicas más plausibles de realizar por los médicos en formación, de acuerdo a la epidemiología nacional; o bien considerar pasantías obligatorias para adquirir dichas destrezas.

\section{Agradecimientos}

Queremos agradecer a la Dra. Mariela Torrente A. por su colaboración en la revisión del manuscrito.

\section{BIBLIOGRAFÍA}

1. BerRocal J. Entrenamiento para Residentes en O.R.L. Rev Med Costa Rica 1975; 42(452): 121-5.

2. Programa de Formación de Especialistas en Otorrinolaringología. Departamento de Otorrinolaringología, Facultad de Medicina, Universidad de Chile. Unidad Docente Campus Occidente, Hospital San Juan de Dios, 2007.

3. Razeto L. Ei San Juan II. Trabajo presentado en la Reunión de la Sociedad de Otorrinolaringología, Medicina y Grugía de cabeza y auello. Octubre 2004.

4. MaAss JC, NASER A. Encuesta de adquisición de destrezas quirúrgicas en el programa de formación de especialistas de Otorrinolaringología en Chile. Rev Atorrinolaringol Or Cabeza Quello 2004; 64: 214-22.

Dirección: Dra Carolina Castillo T.

Huérfanos 3255, Santiago.

Fono: 5741985

Email: carolina.ct@gmail.com 